\title{
ОСОБЕННОСТИ ФОРМИРОВАНИЯ СТРАТЕГИИ ЭКОНОМИЧЕСКОГО РОСТА НЕФТЕДОБЫВАЮЩЕЙ ПРОМЫШЛЕННОСТИ
}

\author{
Г. В. Давыдова, О. С. Козлова \\ Байкальский государственный университет, г. Иркутск, Российская Федерация
}

\section{Информация о статье}

Дата поступления

21 августа 2017 г.

Дата принятия к печати 28 февраля 2018 г.

Дата онлайн-размещения 30 марта 2018 г.

\section{Ключевые слова}

Особенности фрормирования стратегии; экономический рост; нефтедобывающая промышленность

\begin{abstract}
Аннотация
В статье рассматриваются особенности фрормирования стратегии экономического роста нефтедобывающей промышленности, которые позволят развивать отрасль в условиях сложившихся рыночных отношений. В результате исследования выявлено, что для фрормирования стратегии экономического роста нефтедобывающей промышленности необходимо использовать в комплексе системный, территориально-отраслевой и эволюционный подходы, руководствоваться определенными принципами, разрабатывать стратегию экономического роста отрасли с учетом фраз жизненного цикла, достигнутого уровня экономического роста отрасли, сложившихся направлений развития и факторов. Формируя стратегию экономического роста отрасли, следует учитывать временные рамки, а также процессы экономического, социального и технического характера. Неотъемлемым элементом разработки отраслевой стратегии является необходимость учета рисков и способов предотвращения этих рисков.
\end{abstract}

\section{ASPECTS OF ECONOMIC GROWTH STRATEGY DEVELOPMENT FOR THE OIL UPSTREAM SECTOR}

\author{
Galina V. Davydova, Olga S. Kozlova \\ Baikal State University, Irkutsk, the Russian Federation
}

\author{
Article info \\ Received \\ August 21, 2017 \\ Accepted \\ February 28, 2018 \\ Available online \\ March 30, 2018

\section{Keywords} \\ Aspects of strategy \\ development; economic growth; \\ oil upstream sector
}

\begin{abstract}
The article is dedicated to some aspects of the economic growth strategy development in the oil upstream sector, which will allow developing the industry in the conditions of existing market relations. The research revealed that in order to form the economic growth strategy for the oil industry, the use of comprehensive, territorial-economic and evolutionary approaches is essential, as well as the guidance by certain principles, development of an economic growth strategy for the industry with the glance to the lifecycle phases, attained level of economic growth of the industry, existing course and other factors. In the process of building the economic growth strategy for the industry, it is necessary consider the timeframe, along with the processes of economic, social and technical nature. An integral part of developing an industry strategy is the need to consider the risks, and the ways to prevent them.
\end{abstract}

Переход к стратегии экономического роста является условием выживания и развития отрасли. Для формирования понятия «стратегия экономического роста отрасли» целесообразно иметь в виду:

- повышение экономического роста в условиях рынка выступает как имманентное качество, внутренне присущий признак развития любой хозяйственной системы;

- совершенствование хозяйственной системы в целом и обеспечение экономи-

(ㄷ Г. В. Давыдова, О. С. Козлова, 2018 ческого роста отрасли в настоящее время возможны только с использованием современных технологий;

- стратегию экономического роста отрасли можно представить как совокупность механизмов, способов и управленческих решений, которые необходимы для сохранения действующих и формирования долговременных путей экономического роста.

Именно отраслевой подход при разработке стратегии позволяет не только охва- 
тить группу предприятий, имеющих близкую хозяйственную специализацию, занятых определенным видом деятельности, но и учесть все существующие межхозяйственные взаимосвязи, реализовать экосистемный подход, достичь согласованного развития производственной и социальной составляющих хозяйственной системы. В границах понятия «вид экономической деятельности», как представляется, вообще невозможно использование системного подхода в целях стратегического планирования и управления. Недаром до настоящего времени, несмотря на наличие разработок по уточнению понятия «вид экономической деятельности», не рассматривалась такая категория, как «стратегия развития экономической деятельности» [1-5].

При формировании стратегии экономического роста отрасли стоит учитывать системный, территориально-отраслевой и эволюционный подходы.

Системный подход подразумевает то, что отрасль представляет собой социально-экономическую систему, имеющую как экономическую (производственную), так и социальную и экологическую составляющие. Кроме того, системное представление отрасли предполагает учет внешних и внутренних факторов ее функционирования при разработке стратегических решений.

Применение территориально-отраслевого подхода в методическом плане предполагает, что стратегия экономического роста отрасли должна рассматриваться в тесной взаимосвязи со стратегией экономического роста территории, на которой базируется отрасль. Повышение экономического роста отрасли как неотъемлемый элемент ее развития должно идти в русле развития территории и способствовать этому процессу [там же].

Эволюционный подход представляет собой процесс развития отрасли, сопровождающийся последовательным прохождением фаз жизненного цикла - рождения, зрелости и спада. Одной из основных целей, стоящих перед отраслью в каждой из названных фаз, является повышение экономического роста. Однако задачи, решаемые для достижения указанной цели, будут различны и будут меняться от фазы к фазе. В этой связи, приступая к разработке стратегии экономического роста, для более четкого формулирования ее цели и задач важно определить фазу жизненного цикла, в которой находится отрасль в данный момент времени [там же].

Следовательно, обеспечение экономического роста нефтедобывающей отрасли, осуществляемого на основе стратегического управления, должно быть направлено на решение конкретных задач отраслевого развития и при этом базироваться на определении фазы ее жизненного цикла, обобщении опыта развития нефтедобывающей отрасли в целом в России, отраслей, действующих в других субъектах Российской Федерации, а также учитывать национальную специфику.

Основными составляющими модели разработки и реализации стратегии экономического роста выступают:

- исследование жизненного цикла отрасли, определение фраз жизненного цикла;

- формирование стратегии в зависимости от фраз жизненного цикла;

- необходимость оценки отраслевого потенциала с учетом экономических, социальных и экологических характеристик;

- формирование определенных управленческих решений в виде планов, проектов, программ;

- контроль реализации стратегии (рис. 1).

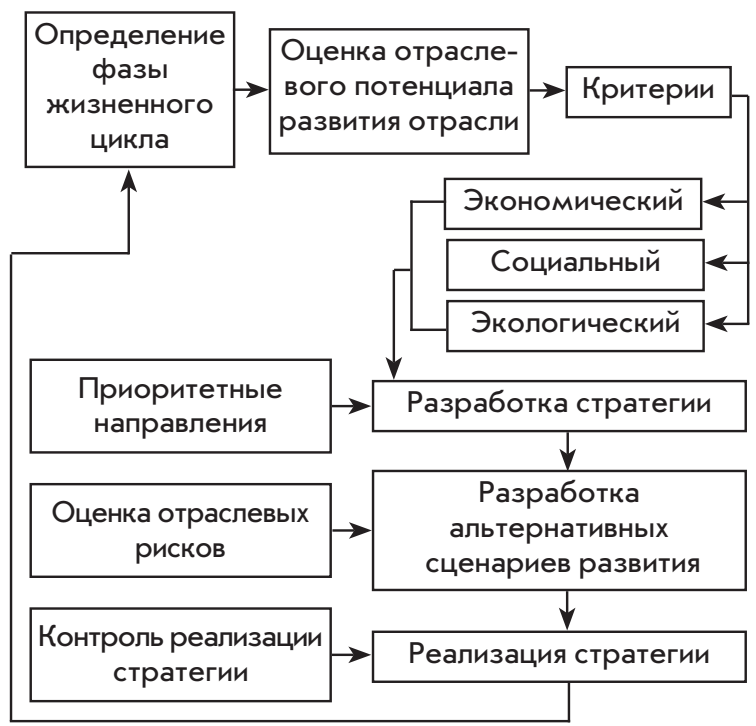

\section{Рис. 1. Логическая модель разработки и реализации стратегии экономического роста отрасли}

При формировании стратегии экономического роста нефтедобывающей отрасли необходимо также учитывать и определенные принципы:

- принцип разумного сочетания федеральных, региональных и частных интересов, который предполагает взаимосвязь частных, региональных и федеральных интересов. Принцип подразумевает решение интересов государства как собственника нефртяных ресурсов, региона как субъекта, обеспечивающего потребность отрасли в трудовых ресурсах, предприятий как объ- 
ектов инфраструктуры, осуществляющих нефтедобывающую деятельность. Распределение выгод от нефтедобывающей деятельности должно стимулировать все заинтересованные стороны;

- принцип эфрфективности, который предполагает развитие отрасли, повышение конкурентоспособности отрасли в пределах обозначенных ресурсов;

- принцип инновационности, который подразумевает использование современных технологий на всех этапах процессов производства и управления;

- принцип многовариантности, при котором предполагается разработка нескольких сценариев стратегического развития [6-8].

Далее рассмотрим методические особенности разработки каждого этапа данной стратегии. В ходе разработки стратегии экономического роста отрасли осуществляется оценка состояния объекта стратегического планирования. Исходным моментом в этом случае является определение фазы жизненного цикла отрасли, кроме того, оценка ее потенциала с учетом влияния на нее территориальных особенностей ффункционирования.

Анализ проводится для того, чтобы установить достигнутый уровень экономического роста отрасли, а также сложившиеся тенденции развития и фракторы, которые повлияли на экономические процессы. Сущность анализа заключается в определении текущего состояния отрасли в сравнении с ожидаемым.

Эфрфективность деятельности, а также курс действий социально-экономических систем зависят прежде всего от того, насколько верно были поставлены цели. Цель представляет собой конечный результат. Цель не всегда совпадает с результатом, так как в ходе ее достижения могут возникнуть побочные эфрфекты, изначально не планировавшиеся.

Специфика объекта управления определяет цель. Стоит выделить главные цели и второстепенные (подцели). Главная цель достигается за счет подцелей, для решения главной цели необходимо, чтобы подцели были взаимосвязаны и направлены на решение в целом главной цели.

Для определения целей и подцелей, их структуры и иерархии целесообразно построение «дерева целей». На рис. 2 представлена структура поочередности решения задач, подцелей, целей.

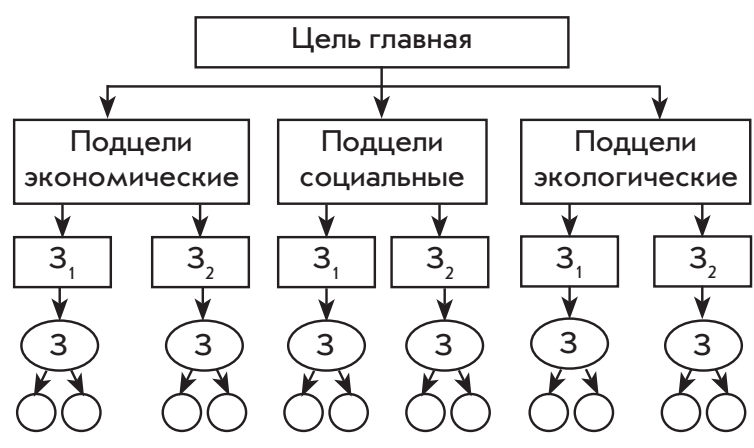

Рис. 2. Дерево целей стратегии экономического роста нефтедобывающей отрасли

Главная цель - обеспечить заданные показатели экономического роста отрасли. Подцели следует разделить на экономические, социальные, экологические.

Задачи, предполагаемые стратегией экономического роста, должны быть преемственны подцелям и направлены на их достижение.

В случае с нефтедобывающей отраслью при формировании задач стратегии необходимо учитывать следующее:

- поскольку повышение темпов экономического роста нефтедобывающей отрасли - основная цель, а задачи являются составляющими этой цели, следовательно, усилия должны быть направлены и на решение задач подцелей;

- разбивка стратегии на отдельные этапы предопределяется требованием обоснованно распределить инновационные мероприятия по временным периодам исходя из необходимости соблюдения преемственности различных этапов инновационного процесса;

- следует также учитывать такие особенности нефтедобывающей отрасли, как раздробленность и качественная неоднородность составляющих еe предприятий. Предполагается, что совершить быстрый переход к инновационному типу развития сможет лишь небольшая часть крупных и средних предприятий. Для малых предприятий, составляющих значительную часть данной отрасли, необходим переходный период, подготовительный этап, в рамках которого должна быть проведена их адаптация к работе в новых условиях [1].

На практике возможно использование одной из нескольких известных базовых стратегий, которые эфффективны при определенных условиях, либо параллельное (в случае непротиворечивости) или последо- 
вательное комплексное применение таких стратегий, как:

- стратегия «ограниченного роста», применяемая для отраслей со стабильной технологией, в которых устанавливаются цели с корректировкой на изменяющиеся условия внешней среды (санкции, иноляция, правовые ограничения и т. д.);

- стратегия "роста», чаще используемая для развивающихся отраслей с быстро меняющейся технологией, когда устанавливается ежегодное превышение уровня развития над достигнутым;

- стратегия «сокращения», или «последнего средства», которая предполагает постановку целей ниже достигнутого уровня. Это происходит в том случае, когда деятельность экономических объектов приобретает устойчивую тенденцию к ухудшению, а попытки изменить ситуацию не приводят к положительному результату;

- комбинированная стратегия, используемая при сочетании вышеперечисленных стратегий. Использование данной стратегии возможно при наличии крупных предприятий, функционирующих в нескольких отраслях.

Базовые стратегии могут быть полезны для постановки целей в условиях неопределенности внешней среды.

Формируя стратегию экономического роста отрасли, следует учитывать временные рамки. При определенных условиях и сценарии развития отрасли (стратегии) должны быть разные.
К числу основных требований, которым должен удовлетворять набор сценариев реализации стратегии отрасли, относятся следующие:

- за счет стратегии должно обеспечиваться повышение экономического роста в долгосрочном периоде;

- за счет стратегии должны решаться и текущие задачи;

- за счет стратегии должен обеспечиваться рост отрасли не только в стране в целом, но и на отдельных территориях;

- необходимость учета и контроля отраслевых рисков;

- взаимосвязь отраслевой стратегии с развитием страны в целом.

Неотъемлемым элементом разработки отраслевой стратегии является необходимость учета рисков. Риск представляет собой сочетание вероятности и последствий наступления неблагоприятных событий в результате воздействия внутренних и внешних фракторов [9-13]. Величина возможных потерь характеризует риск. Часть рисков носит объективно неуправляемый характер (техногенные катастрофы, горно-геологические условия и др.). Стратегия должна учитывать регулируемые риски и предусматривать меры по их снижению.

Предлагаемая авторами матрица жизненных циклов и факторов экономического роста позволит повысить точность разрабатываемой стратегии экономического роста отрасли (рис. 3).

\begin{tabular}{|c|c|c|c|c|c|c|}
\hline \multirow[b]{2}{*}{ Перспективы } & \multirow[b]{2}{*}{ Факторы } & \multicolumn{5}{|c|}{ Фазы жизненного цикла } \\
\hline & & $\begin{array}{c}\text { Вхождение } \\
\text { в рынок, } \\
\text { зарождение }\end{array}$ & $\begin{array}{l}\text { I фраза } \\
\text { роста }\end{array}$ & $\begin{array}{l}\text { II фраза } \\
\text { роста }\end{array}$ & Зрелость & $\begin{array}{c}\text { Уход с рынка } \\
\text { спад }\end{array}$ \\
\hline \multirow{5}{*}{$\begin{array}{c}\text { Кратко- } \\
\text { срочная } \\
\text { перспектива }\end{array}$} & Темпы роста (TP) & TP 1 & TP 2 & TP 3 & TP 4 & TP 41 \\
\hline & $\begin{array}{l}\text { Объем выпускаемой } \\
\text { продукции (ОП) }\end{array}$ & ОП 1 & ОП 2 & ОП 3 & ОП 4 & ОП 41 \\
\hline & Прибыль (П) & $\Pi 1$ & $\Pi 2$ & $\Pi 3$ & $\Pi 4$ & $\Pi 41$ \\
\hline & Рентабельность (R) & R 1 & R 2 & R 3 & R 4 & R 41 \\
\hline & $\begin{array}{l}\text { Необходимые капиталь- } \\
\text { ные вложения (КВ) }\end{array}$ & & & & & \\
\hline \multirow{5}{*}{$\begin{array}{c}\text { Долго- } \\
\text { срочная } \\
\text { перспектива }\end{array}$} & Темпы роста (ТP) & - & TP 1 & TP 2 & TP $21+$ TP 31 & TP 4 \\
\hline & $\begin{array}{l}\text { Объем выпускаемой } \\
\text { продукции (ОП) }\end{array}$ & - & ОП 1 & ОП 2 & ОП 21 + ОП 31 & ОП 4 \\
\hline & Прибыль (П) & - & $\Pi 1$ & $\Pi 2$ & $\Pi 21+\Pi 31$ & $\Pi 4$ \\
\hline & Рентабельность (R) & - & R 1 & R 2 & R 21 + R 31 & R 4 \\
\hline & $\begin{array}{l}\text { Необходимые капиталь- } \\
\text { ные вложения (КВ) }\end{array}$ & - & KB 1 & KB 2 & KВ $21+K B 31$ & КВ 4 \\
\hline
\end{tabular}

Рис. 3. Матрица жизненных циклов и факторов экономического роста 
Из сказанного выше следует, что для формирования стратегии экономического роста нефтедобывающей промышленности необходимо использовать в комплексе системный, территориально-отраслевой и эволюционный подходы, руководствоваться определенными принципами, разрабатывать стратегию развития отрасли с учетом фраз жизненного цикла, достигнутого уровня экономического роста отрасли, сложившихся тенденций развития и факторов. Формируя стратегию экономического роста отрасли, следует учитывать временные рамки, а также процессы экономического, социального и технического характера. Неотъемлемым элементом разработки отраслевой стратегии является необходимость учета рисков и способов их предотвращения.

\section{СПИСОК ИСПОЛЬЗОВАННОЙ ЛИТЕРАТУРЫ}

1. Акулич О. В. Особенности формирования стратегии роста конкурентоспособности отрасли / О. В. Акулич / / Baikal Research Journal. - 2011. - № 5. - Режим доступа: http://brj-bguep.ru/reader/article.aspx?id=9687.

2. Дмитриева О. М. Состояние, факторы и стратегии развития нефтедобывающей отрасли / О. М. Дмитриева // Проблемы экономики и управления нефтегазовым комплексом. - 2008. - № 8. - С. 14-22.

3. Черников А. П. Стратегия развития ресурсных регионов Сибири : учеб. пособие / А. П. Черников. Иркутск : Изд-во БГУЭП, 2003. - 173 с.

4. Черников А. П. Разработка методов выбора стратегий регионального развития / А. П. Черников // Совершенствование управления и перспективы развития социально-экономических систем : сб. науч. тр. / А. П. Черников. - Иркутск, 2003. - С. 43-44.

5. Асланян А. А. Стратегия развития отраслей экономики как фрактор устойчивого развития региона / А. А. Асланян, Д. В. Карпенко, Е. П. Кудряшова / / Экономика и социум. - 2016. — № 12-1 (31). - С. $222-227$.

6. Куценко А. В. Формирование стратегий, ориентированных на развитие инновационного потенциала промышленных компаний (на примере нефтегазовой отрасли) / А. В. Куценко // Международные маркетинговые стратегии компаний в посткризисных условиях. Развитые и развивающиеся рынки, СНГ и Россия : материалы Междунар. науч.-практ. конф., Москва, 9-10 дек. 2010 г. - М. : Изд-во РУДН, 2011. — С. 105-109.

7. Богоявленский В. И. Состояние и стратегия развития нефтегазовой отрасли в России и в ее Арктической зоне / В. И. Богоявленский, И. В. Богоявленский // Государственный аудит. Право. Экономика. - 2017. № $1 .-$ С. 37-43.

8. Даукаев А. А. Нефтегазовая отрасль как сложная система и стратегия ее развития / А. А. Даукаев // Естественные и технические науки. - 2008. - № 5 (37). - С. 149-150.

9. Проблемы и перспективы развития промышленности : сб. науч. тр. / под ред. А. И. Бирюковой. Иркутск : Изд-во БГУЭП, 2013. - 134 с.

10. Самаруха В. И. Формирование конкурентных преимуществ регионов / В. И. Самаруха, Т. Г. Краснова // Известия Иркутской государственной экономической академии. - 2008. - № 4. - С. 26-29.

11. Мартынихин В. В. Перспективы развития нефтегазовой инфраструктуры в Иркутской области / В. В. Мартынихин, С. А. Богидаев // Публичное управление и территориальное развитие: современные тенденции, проблемы и перспективы : материалы междунар. науч.-практ. конф. - Иркутск, 2013. - С. 78-82.

12. Шмаль Г. И. Основой государственной стратегии развития нефтегазовой отрасли должна стать инновационная составляющая / Г.И.Шмаль // Нефртяное хозяйство. - 2012. — № 5. - С. 4-9.

13. Маленков Ю. А. Разработка стратегий развития отраслей, хозяйственных комплексов и кластеров / Ю. А. Маленков, С. Р. Древинг. - М. : Проспект, 2009. - 264 с.

\section{REFERENCES}

1. Akulich O.V. Peculiarities of Forming Economic Sector Competitive Growth Strategy. Baikal Research Journal, 2011, no. 5. Available at: http://brj-bguep.ru/reader/article. aspx?id=9687. (In Russian).

2. Dmitrieva O. M. Status, Factors and Development Strategies of the Upstream Sector. Problemy ekonomiki $i$ upravleniya neftegazovym kompleksom = Economic and governance challenges in the oil and gas sector, 2008, no. 8, pp. 14-22. (In Russian).

3. Chernikov A. P. Strategiya razvitiya resursnykh regionov Sibiri [Development Strategies of Siberian Resource Regions]. Irkutsk, Baikal State University of Economics and Law Publ., 2003. 173 p.

4. Chernikov A. P. Development of Approaches to Regional Growth Strategy Selection. Sovershenstvovanie upravleniya i perspektivy razvitiya sotsial' no-ekonomicheskikh sistem [Management development and growth prospects of social-economic systems]. Irkutsk, Baikal State University of Economics and Law Publ., 2003, pp. 43-44. (In Russian).

5. Aslanyan A. A., Karpenko D. V., Kudryashova E. P. Strategy of the Development of Branches of Economy as an Aspect of Sustainable Growth of the Region. Ekonomika i sotsium = Economics and society, 2016, no. 12-1 (31), pp. 222-227. (In Russian).

6. Kutsenko A. V. Forming the Strategies with a Focus on Development of Innovative Capacity of Industrial Companies (in the Context of the Oil and Gas Industry). Mezhdunarodnye marketingovye strategii kompanii $\checkmark$ postkrizisnykh usloviyakh. Razvitye i razvivayushchiesya rynki, SNG i Rossiya. Materialy Mezhdunarodnoi nauchno-prakticheskoi konferentsii, Moskva, 9-10 dekabrya 2010 g. [International Marketing Strategies of Companies in the Post-Crisis World. Developed \& Emerging Markets, CIS \& Russia. Materials of International Re- 
search Conference, Moscow, December 9-10, 2010]. Moscow, People's Friendship University of Russia Publ., 2011, pp. 105-109. (In Russian).

7. Bogoyavlensky V. I., Bogoyavlensky I. V. Status and Development Strategies of the Upstream Sector in Russia and Russian Polar Zone. Gosudarstvennyi audit. Pravo. Ekonomika = State Audit. Law. Economics, 2017, no. 1, pp. 37-43. (In Russian).

8. Daukaev A. A. The Oil and Gas Sector as a Complex System and Its Development Strategy. Estestvennye $i$ tekhnicheskie nauki = Natural and technical sciences, 2008, no. 5 (37), pp. 149-150. (In Russian).

9. Biryukova A. I. (ed.). Problemy i perspektivy razvitiya promyshlennosti [Challenges and Opportunities of Industrial Growth]. Irkutsk, Baikal State University of Economics and Law Publ., 2013. 134 p.

10. Samarukha V. I., Krasnova T. G. Formation of Competitive Advantages of Regions. Izvestiya Irkutskoi gosudarstvennoi ekonomicheskoi akademii = Izvestiya of Irkutsk State Economics Academy, 2008, no. 4 (60), pp. 26-29. (In Russian).

11. Martynikhin V. V., Bogidaev S. A. Development Outlook on Oil and Gas Infrastructure in Irkutsk Oblast. Publichnoe upravlenie $i$ territorial'noe razvitie: sovremennye tendentsii, problemy i perspektivy. Materialy Mezhdunarodnoi nauchno-prakticheskoi konferentsii. [Public management and spatial development: modern trends, challenges and opportunities. Materials of International Research Conference]. Irkutsk, Baikal State University of Economics and Law Publ., 2013, pp. 78-82. (In Russian).

12. Shmal G. I. The innovative component should become the basis to the national strategy of the oil and gas sector development. Neftyanoe khozyaistvo = Oil industry, 2012, no. 5, pp. 4-9. (In Russian).

13. Malenkov Yu. A., Dreving S. R. Razrabotka strategii razvitiya otraslei, khozyaistvennykh kompleksov $i$ klasterov [Development of Growth Strategies for Industries, Economic Complexes and Clusters]. Moscow, Prospekt Publ., 2009. 264 p.

\section{Информация об авторах}

Давыдова Галина Васильевна - доктор экономических наук, профессор, кафедра экономики и управления бизнесом, Байкальский государственный университет, 664003, г. Иркутск, ул. Ленина, 11, e-mail: kafles@isea.ru.

Козлова Ольга Сергеевна - аспирант, кафедра экономики и управления бизнесом, Байкальский государственный университет, 664003 г. Иркутск, ул. Ленина 11, e-mail: Okozlova81@mail.ru.

\section{Для цитирования}

Давыдова Г. В. Особенности формирования стратегии экономического роста нефтедобывающей промышленности / Г.В.Давыдова, О.С.Козлова // Известия Байкальского государственного университета. - 2018. - Т. 28, № 1. - С. 74-79. DOI: $10.17150 / 2500-2759.2018 .28(1) .74-79$.

\section{Authors}

Galina V. Davydova - DSc in Economics, Professor, Department of Economics and Business Management, Baikal State University, 11 Lenin St., 664003, Irkutsk, the Russian Federation, e-mail: kafles@ isea.ru.

Olga S. Kozlova - PhD student, Department of Economics and Business Management, Baikal State University, 11 Lenin St., 664003, Irkutsk, the Russian Federation, e-mail: Okozlova81@mail.ru.

\section{For citation}

Davydova G. V., Kozlova O. S. Aspects of Economic Growth Strategy Development for the Oil Upstream Sector. Izvestiya Baykal'skogo gosudarstvennogo universiteta = Bulletin of Baikal State University, 2018, vol. 28, no. 1, pp. 74-79. DOI: 10.17150/2500-2759.2018.28(1).74-79. (In Russian). 